\title{
Study on Spatio-Temporal Characteristics of Shared Single Carriage Travel-This Once in the Central Urban Area of Mianyang City
}

\author{
Tingting An, Langong Hou \\ School of Civil Engineering and Architecture, Southwest University of Science and Technology, Mianyang, China \\ Email:2278146883@qq.com, soundskyhlg@163.com
}

How to cite this paper: An, T. T., \& Hou, L. G. (2020). Study on Spatio-Temporal Characteristics of Shared Single Carriage Travel-This Once in the Central Urban Area of Mianyang City. Open Journal of Social Sciences, 8, 196-205.

https://doi.org/10.4236/jss.2020.87016

Received: June 10, 2020

Accepted: July 18, 2020

Published: July 21, 2020

Copyright $\odot 2020$ by author(s) and Scientific Research Publishing Inc. This work is licensed under the Creative Commons Attribution International License (CC BY 4.0).

http://creativecommons.org/licenses/by/4.0/

(c) (i) Open Access

\begin{abstract}
Shared bicycles affect the daily travel mode of urban residents, but also slowly change the spatial pattern of cities. Aiming at the challenges caused by the growth of shared bicycle storm to urban management, python and research were used to obtain the data of shared bicycle use in the central urban area of Mianyang City. Based on ArcGIS nuclear density analysis tool, the spatiotemporal characteristics of shared bicycle use were analyzed. The results showed that: the use of shared bicycle was greatly affected by the weather, the number of rides on weekends relative to weekdays was small and there were obvious characteristics of morning and evening peak time on weekdays; the distribution characteristics in space were consistent with the POI distribution characteristics, and different urban functions had a certain impact on the travel density of shared bicycle; finally, the study suggested that the future planning of shared bicycle facilities should use big data to construct a bicycle market supply and demand statistical system, and target the placement layout and intelligent dispatching by region, time period and frequency.
\end{abstract}

\section{Keywords}

Shared Bicycle, Spatiotemporal Data, Travel Characteristics, Central Urban Area of Mianyang

\section{Introduction}

The operating model of "Internet+" has promoted the development of shared bicycles, which is a new business model of shared economy. Based on the concept of travel, it is widely welcomed by the public. The emergence of shared bi- 
cycles solves the problem of "last kilometer" urban transportation, improves the efficiency of resident travel, and reduces the environmental pollution caused by transportation. However, the sharing of bicycle storm investment has not formed a perfect management and operation system, and many problems have been exposed after investment. For example, the phenomenon of "difficult to borrow a car and difficult to park" hinders the sustainable development of shared bicycles, and the random parking brings serious challenges to urban management. Faced with the problems caused by shared bicycles, urban spatial planning, urban management, operators and so on need to respond. From the perspective of urban planning, the key to solve the problem of shared bicycle is the optimal allocation of space resources, involving the planning layout of lanes, parking facilities, etc. In the seemingly irregular "Brownian movement" of shared bicycles, there are actually objective laws. As long as people's travel laws are correctly understood, there are rules for the parking of shared bicycles. Therefore, it is of great theoretical and practical significance to carry out the study of riding law of shared bicycle users at present, which can provide guidance for the layout of parking facilities of shared bicycle, and at the same time, it is helpful to explore the characteristics of urban spatial vitality distribution.

The research on bicycles at home and abroad mainly focuses on public bicycles, mainly discusses the development history and mode, spatial characteristics of travel time, satisfaction evaluation, supply and demand matching, site selection, and built environmental impact. At present, there are few related studies on shared bicycles, and the content is mainly from the perspective of shared economy, focusing on operation, supervision, governance and other aspects.

Buckd (2012) focused on analyzing the effects of urban built environment, land use, public transportation, weather, and travel time on public bicycles. Guo et al. (2017) mainly studied the spatiotemporal characteristics of public bicycles and the layout planning of rental sites. Wang et al. (2018) analyzed the factors affecting public bicycle riding with this time in Xi'an. Ma et al. (2018) concluded that shared bicycles and public bicycles can achieve complementarity, in order to promote urban residents to travel more convenient and comfortable. Deng et al. (2017) studied the facility planning under shared bicycles to promote the optimal layout of urban facilities, and simply analyzed the statistical attributes of shared bicycles. Zhang et al. (2017) analyzed the uneven distribution of shared bicycles, car theft and other behaviors from the Perspective of supply side, emphasizing the important role of the government in appropriate intervention. Qin \& Wang (2017) believed that the shared bicycle faces the dual problems of government failure and market failure, and the three-party coordination mechanism of government, market and society should be constructed. However, there are few studies on the layout of shared bicycle planning from the perspective of time-space behavior characteristics of residents' travel. In addition, the existing research mostly describes the characteristics from the urban point of view, and the analysis of urban area scale is relatively lacking. 
Therefore, this study uses the Harrow bicycle data of the central area of Mianyang City, through the time statistics and spatial visualization analysis of the shared bicycle riding, explores the time-space characteristics of the shared bicycle flow and use at the urban scale and different types of functional area scales, and further discusses its supply and demand matching problem, and proposes the corresponding optimization strategies in order to provide a reference for realizing the accurate delivery and allocation of shared bicycles and better meeting the travel needs of citizens.

\section{Overview of Study Area, Data Source and Analysis Method}

\subsection{Overview of Study Area}

The study area includes the area surrounded by Chengmianguang Expressway, planned Mianyu Expressway, South Ring High Speed Connection Line and the planned construction land range of agricultural science and technology area, including Fucheng District, Youxian District, Hi-tech Industrial Development Zone, Jingkai District and Kechuang Park, with an area of 465 square kilometers. A total of 538 educational facilities are planned in the central urban area, including 6 district stadiums, 6 gymnasiums, 8 swimming pools (gymnasiums), 70 community comprehensive sports grounds, 52 comprehensive fitness centers, and 150 resident fitness facilities. There were 12 municipal cultures, 20 districtlevel cultural facilities, 173 community-level cultural facilities, and 232 medical and health facilities.

\subsection{Data Sources}

For the study comparing weekday and weekend shared bike ride characteristics, Crawling mianyang downtown by Python web crawler (longitude range: 104.49E - 105.04E; Harrow bike usage data updated hourly throughout the day from October 10, 2018 to October 14, 2018, including user ID, bike ID, bike type, bike path, latitude, and bike time at that location. The average number of bicycles involved per day is about 100,000 . These data are based on the completely spontaneous riding behavior of users. Among them, October 10 (Wednesday) and October 14 (Sunday) 2018 are sunny days, the air temperatures are $12^{\circ} \mathrm{C}-23^{\circ} \mathrm{C}$ and $12^{\circ} \mathrm{C}-18^{\circ} \mathrm{C}$, respectively, and the air quality is good and excellent, respectively. These two days have similar weather conditions, are comparable, and have no special events. They are conventional working days and rest days. Therefore, they are the data left in the unconscious daily riding of users, which can accurately reflect the use characteristics of shared bicycles to some extent.

In addition, the monthly cycling status of Haruo bicycle in Mianyang City in 2018 and the daily cycling volume data in October 2018 (from Haruo bicycle Company in Mianyang City) were obtained, and all POI point data in the central urban area of Mianyang City were obtained through python, covering 15 categories including residential, office, cultural, catering, commercial, scenic spots, and bus stations, in order to study the relationship between various spatial elements 
of POI and the spatial distribution pattern of shared bicycles.

\subsection{Analytical Methods}

In this study, Python and investigation were used to obtain the use data of Harrow bicycle in the central urban area of Mianyang City. This study focuses on the analysis of big data of Shared bikes. Big data acquisition of Shared bikes is also the difficulty of this experiment. Generally speaking, the capture idea of bike-sharing location data is to capture the whole area by Python web crawler using the longitude and latitude cycle of the return area. The specific idea is to find the data interface and disguise the browser head as a mobile phone browser. Because at ordinary times, we use mobile phone positioning to get information about Shared bikes around the location. The data interface comes from the real-time interface of bike-sharing APP. The API for the data returns all bike locations in a square area, with up to 60 bikes at a time. Therefore, as long as we move according to the area by area, we can capture the data of the bicycle position in the whole large area. A circular statement can be used to move from one area to another. In addition, some of the research data were obtained through field investigation, and the Shared bike data were specifically obtained from relevant units such as Mianyang Natural Planning Bureau and Mianyang Haruo Bicycle Company, which ensured the data reliability. Excel and Arc GIS software were used to clean the original data, and the distribution points of bicycle were further obtained. The latitude and longitude of each bicycle were counted by Excel software, and the processed data table was further converted into geographic information system (GIS) point data. The time-space distribution characteristics of bicycle use were analyzed using density analysis tools.

\section{Time-Space Characteristics of Riding Behavior}

\subsection{Time Characteristics of Cycling Behavior}

\subsubsection{Monthly Characteristics of Riding Behavior}

Figure 1 shows the 12-month riding volume of harrow shared bicycles in 2018, with some differences in resident riding volume in each month of 2018, which began to rise steadily between January and April, fluctuated little from May to August, was relatively high in September and October, peaked in October, then decreased abruptly in November and December, and decreased to a minimum in December. The monthly average in 2018 was 2.3 million. It can be seen from the analysis that there is a certain effect of month on the amount of riding. Considering the weather temperature, humidity and other aspects in September and October, the number of rides in September increased for August, which was related to the start of each school in September, and students chose to ride shared bicycles up and down school, so the number of rides in September and October accounted for the highest proportion of the year, the weather temperature from November to February was the lowest in the year, and the number of shared bicycles decreased correspondingly. At the same time, Figure 2 reflects that 


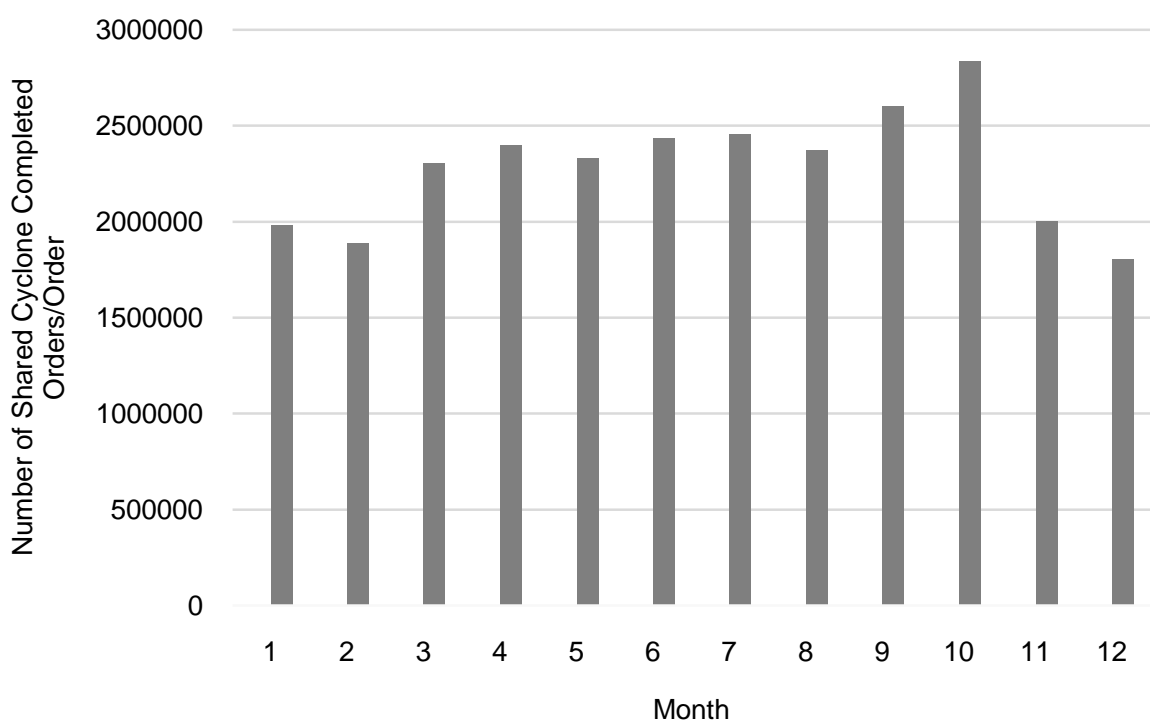

Figure 1. Monthly distribution map of shared bicycle riding volume in 2018.

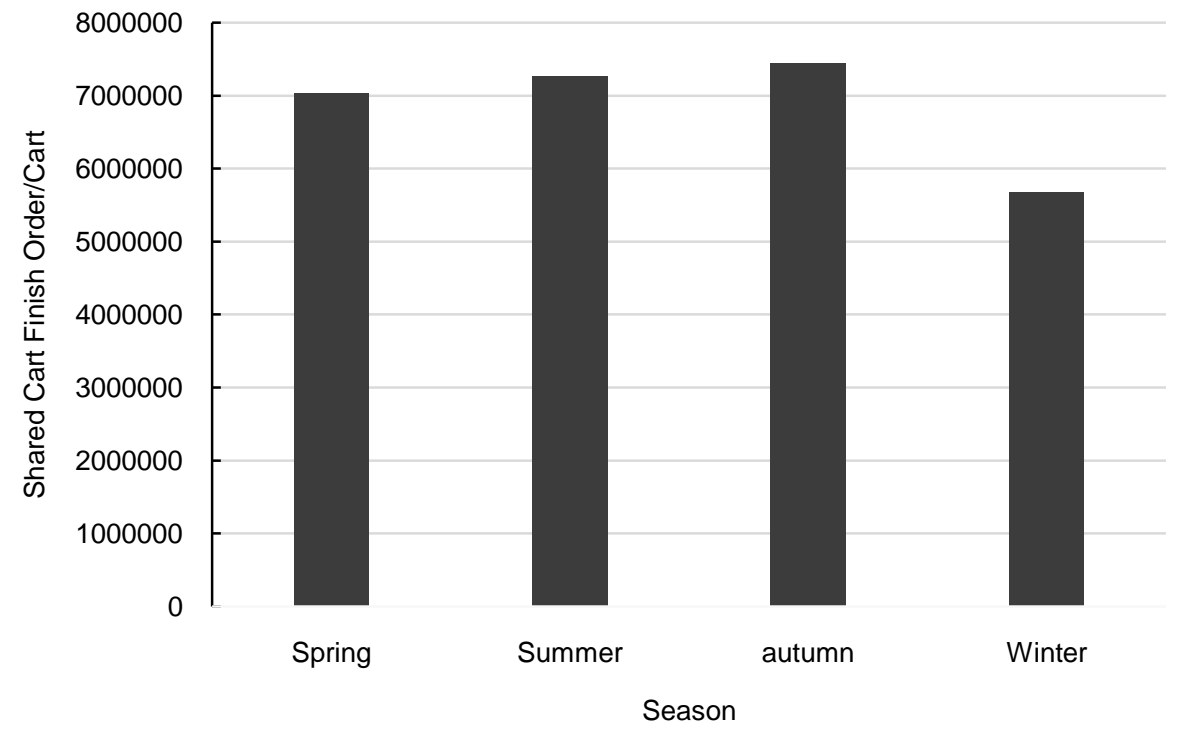

Figure 2. Seasonal distribution diagram of shared cycling volume in 2018.

different seasons also have an effect on the amount of riding, with the largest amount of riding in autumn and the smallest amount of riding in winter. Because low winter temperature and hot summer will affect the amount of shared bicycle riding to some extent, hot or cold weather reduces the heat of residents choosing shared bicycle travel, and pleasant autumn and spring increase the probability of residents choosing shared bicycle travel, it can be seen that weather factors have a significant impact on the amount of shared bicycle riding.

\subsubsection{Weekly Characteristics of Riding Behavior}

Taking the analysis of Harrow shared bicycle riding in October 2018 as a rule, there was a significant regularity in the shared bicycle riding within one week in Figure 3, of which the weather on October 6, October 7, October 13, October 14, 
October 20, October 21, October 27 and October 28 was the weekend, but the weather on October $6,7,8,13,17,18$ and 19 was light rain, and the amount of shared bicycle riding was significantly less, which showed that the shared bicycle travel was affected by certain weather factors. From Figure 4, it can be seen that the number of rides on shared bicycles showed regular changes in October, and among the four weeks in October, the number of rides on weekends (October 6 , $7,13,14,20,21,27$, and 28) was the smallest, and the number of rides on weekdays increased, all of which showed a decrease in the number of rides on weekends compared with weekdays. In order to reduce the influence of weather conditions on the study results, the week characteristics of riding behavior were analyzed in the week with cloudy weather conditions and excellent air conditions, which was specific from Monday, October 22, 2018 to Sunday, October 28, 2018 , and the user riding volume distribution map within the week was obtained. As shown in Figure 5, on October 22, the amount of shared bicycle riding on October 26 was generally greater than that on October 27 and 28, the inflection point of decline occurred on October 27, the amount of riding on October 28 was the lowest, and the amount of riding on working days from October 29 showed an upward trend. Among them, the number of rides on October 24 was relatively reduced due to light rain, but it was also greater than the number of rides on weekends. In general, by the weekend, the amount of riding decreased

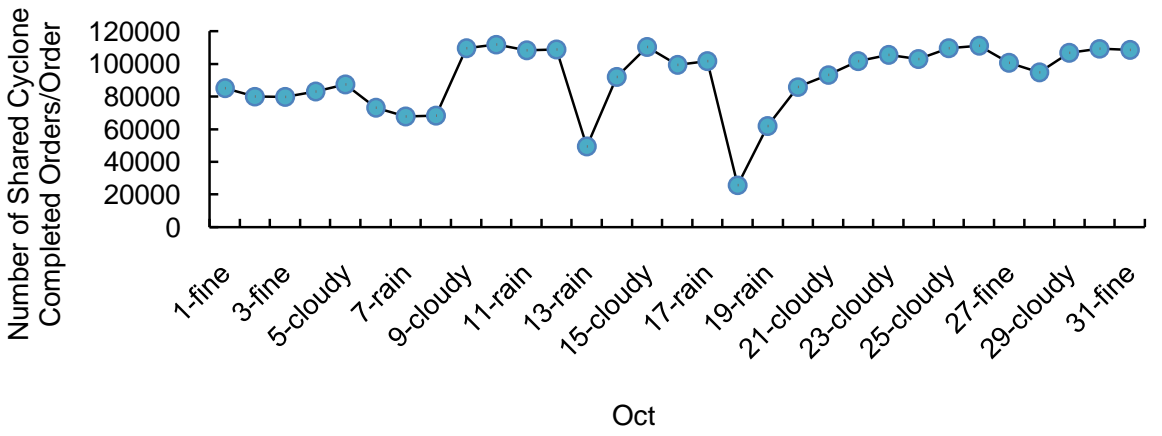

Figure 3. Oct ride profile.

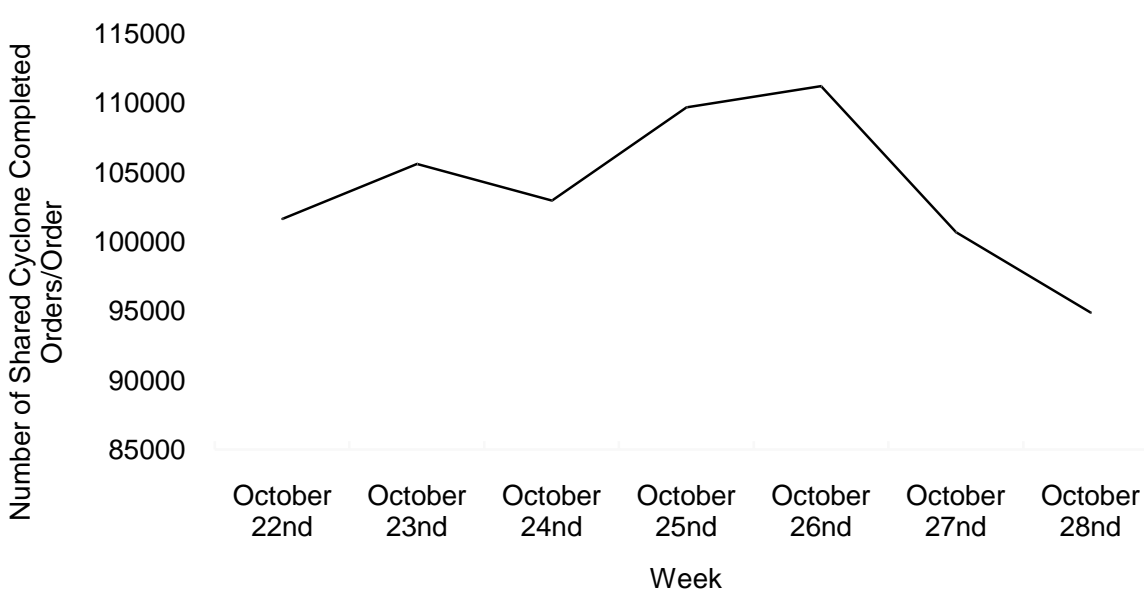

Figure 4. Circumferential distribution plot. 


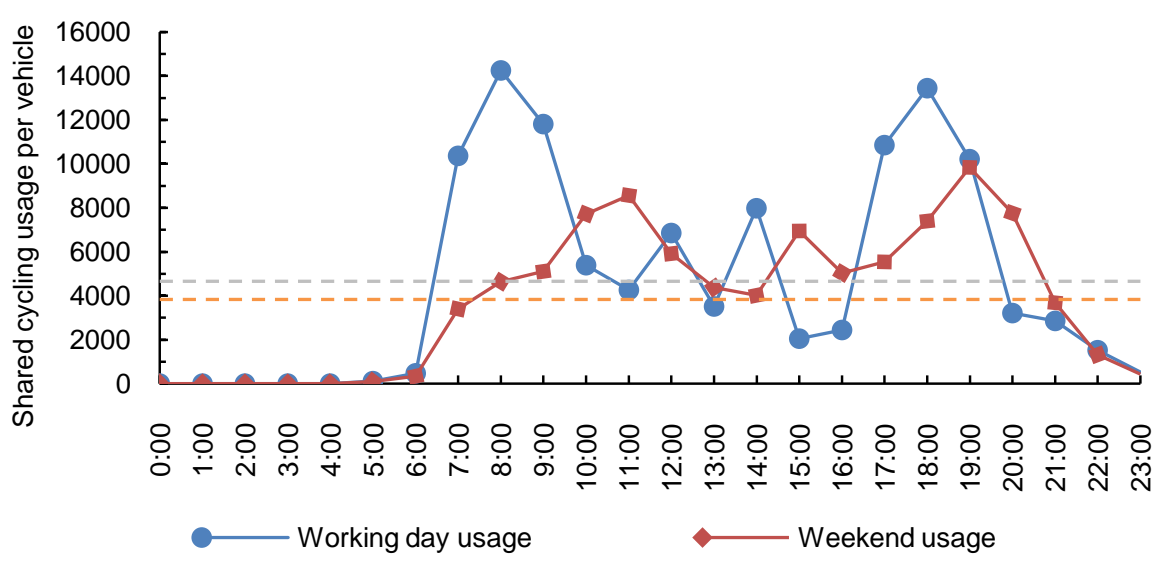

Figure 5. Distribution plot of riding volume in one day.

significantly, and the amount of riding on the weekend was less than that on the weekday. It can be seen that there is a significant difference in the use of shared bicycles between working days and rest days. Considering that residents choose to share bicycle travel purposes mostly for commuting and going to and from school, resulting in a greater amount of riding on weekdays than on weekends.

\subsubsection{Daily Characteristics of Riding Behaviour}

Wednesday, October 10, 2018 and Sunday, October 14, 2018 were selected for the full analysis. The hourly interval of the data of the used bicycles on working days and rest days is counted once, and the time distribution curve of the use of bicycles on working days and rest days is obtained, respectively (Figure 5). The results showed that the riding behavior on weekdays had a certain regularity, forming a significant morning and evening peak and a small afternoon peak phenomenon, which lasted from 00:00 to 5:00, the amount of riding was very small, the amount of riding began to increase at 6:00, and the early peak period was 7:00 - 9:00, in which the peak occurred at 8:00, and the small afternoon peak period was 11:00 - 12:00 and 13:00 - 14:00, the sudden rise and fall phenomenon was obvious, perhaps the dining activity of some users at noon triggered a certain close riding behavior; the late peak period was 17:00 - 19:00, and the peak occurred. At 18:00, a large number of life riding behaviors (shopping, shopping, distraction, etc.) were included after work, and the peak duration was the longest. It was characterized by a more moderate increase in the number of bicycles used. The late peak was slightly lower than the early peak. Considering that after work at night, the number of people who chose walking mode increased. The overall use intensity of bicycles on rest days was lower than that on working days (the average consumption was 3834 vehicles/hour), and there was no obvious early noon peak, but a late peak in the duration was formed. On rest days, life riding behavior occurs, the riding time is more balanced, there is no obvious morning and evening peak phenomenon, the user's recreational and leisure riding behavior in the evening forms the peak of Harrow bicycle consumption. The morning and evening peak is the time when the demand of rid- 
ing traffic is the largest, and it is also an important time to test the supply and demand bearing capacity of riding facilities.

\subsection{Spatial Characteristics of Riding Behavior}

Five core areas with the largest human flow, building density and high road network density in the central urban area were selected for analysis. They are five regions: Cade Plaza District, Tieniu Plaza District, Wuyi Plaza District, Youth Plaza District and Wanda Plaza District, of which the area of Cade Plaza is 12.5 $\mathrm{km}^{2}$, the area of Tieniu Plaza is $9.9 \mathrm{~km}^{2}$, the area of Wuyi Plaza is $23.6 \mathrm{~km}^{2}$, the area of Youth Plaza is $16.2 \mathrm{~km}^{2}$ and the area of Wanda Plaza is $19.6 \mathrm{~km}^{2}$. According to the current situation of land use in the central urban area, the commercial office function is the main function in the Cade Square and Wanda Square areas, the commercial, residential and leisure functions account for a certain proportion in the Tiniu Square area, and the residential and leisure functions are the main in the May Day and Youth Square areas. According to Figure 6, among the five regions, Wuyi Square, Cade Square and Wanda Square had significantly greater weekday use than weekend use, and there was little difference between weekday riding and weekend riding in Tieniu Square, and weekend riding was slightly greater than weekday riding. Among them, the number of rides on weekdays in the youth square area was much smaller than that on weekends.

\section{Conclusion}

In this paper, the spatial distribution characteristics of shared bicycle time in Mianyang City are analyzed by using the shared bicycle riding data in combination with land use classification data and POI data. The specific research conclusions are as follows:

1) The travel of shared bicycles is greatly affected by the weather, the season is different, and there are differences in the amount of riding, with the highest amount of riding in autumn, followed by spring and summer, the least amount of riding in winter, and a significant decrease in the amount of riding on rainy days compared with sunny days.

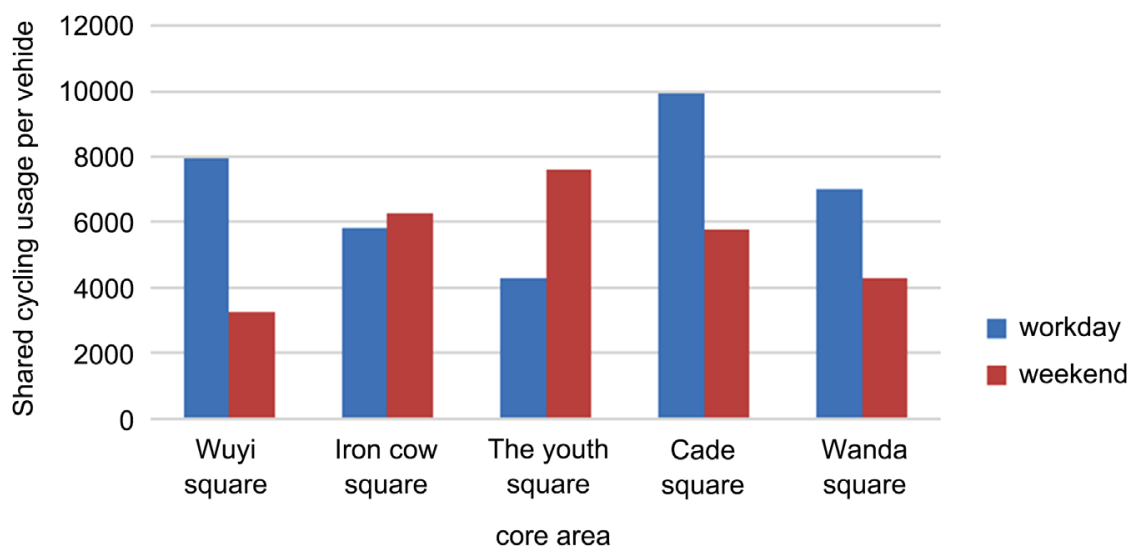

Figure 6. Distribution chart of weekdays and weekend rides in core area. 
2) Compared with weekdays, the amount of riding decreased significantly on weekends. It can be seen that the main purpose of residents using shared bicycle is daily commuting, commuting and school groups, and more life and recreational riding behaviors on weekends. There was a significant difference in the pattern of shared bicycle travel between weekdays and weekends. Shared bicycle travel on weekdays has obvious characteristics of morning and evening peaks and small afternoon peaks. Weekend travel has no obvious morning and evening peak, riding time is more balanced, evening users' recreational, leisure riding behavior formed the peak of shared bicycle consumption.

3) The number of rides in different areas was different on weekdays and weekends. On weekends, the proportion of cars in Cade Square, Wanda Square area with work nature, and May 1 Square with residential nature decreased significantly, while the number of rides in Iron Bull and Youth Square area with rest and entertainment nature increased, while on weekdays, the number of rides in Cade Square and Wanda Square area increased. The spatial distribution characteristics of shared bicycles are obviously consistent with the POI distribution characteristics. It can be seen that the spatial distribution characteristics of shared bicycles also reflect the spatial morphology of cities. Combined with the land use status of central areas, different types of urban functions have a certain impact on the travel density of shared bicycles.

This paper studies the spatiotemporal characteristics of shared bicycle travel, aiming to find the characteristics of riding demand and timely air distribution of shared bicycle at different time points in different regions, and puts forward development suggestions such as standardizing and guiding the planning of shared bicycle parking facilities in Mianyang City, optimizing the layout of non-motor vehicle passages, and improving the setting of riding space environment from the perspective of urban planning. Therefore, in the urban planning, we should combine the sharing of bicycle travel law and POI situation to carry out reasonable bicycle delivery and facility construction, which can not only meet the travel needs of urban population with high efficiency, but also reduce road congestion, road virtual equipment and other circumstances.

There are still some shortcomings in this study. Sharing the needs, subjective feelings and socioeconomic attributes of bicycle users are also important factors affecting their use of bicycle travel, and sharing the characteristics of bicycle travel needs to be further explored.

\section{Conflicts of Interest}

The authors declare no conflicts of interest regarding the publication of this paper.

\section{References}

Buckd, B. (2012). Bike Lane and Other Determinants of Capital Bike Share Trips. Transportation Research Board 91st Annual Meeting, Washington DC. 
Deng, L. F., Xie, Y. H., \& Huang, D. X. (2017). Research on Shared Cycling Facility Planning Based on Riding Space-Time Data. Planner, 33, 82-88.

Guo, S. P., Yen, F., \& Yin, Q. Y. (2017). Spatial Characteristics of Urban Public Bicycle Travel Time. Planner, 33, 112-118.

Ma, S. H., Yang, Y., \& Wang, Y. Q. (2018). Research on Public Bicycle Development under the Influence of Shared Bicycle. Transportation Systems Engineering and Information, 18, 231-236.

Qin, Z., \& Wang, Q. (2017). A Tripartite Synergy Mechanism for Sharing Economic Deductions: Illustrating Shared Cars. Reform, 5, 124-134.

Wang, Y., Liu, Y., Ji, S. et al. (2018). Bicycle Lane Condition and Distance: Case Study of Public Bicycle System in Xi'an, China. Journal of Urban Planning and Development, 144, 156-162. https://doi.org/10.1061/(ASCE)UP.1943-5444.0000436

Zhang, Z. H., Lin, X. Y., \& Zhang, Y. P. (2017). Economic Essence Analysis of Existing Problem of Shared Single Cars from Supply Side Perspective. Urban Development Research, 24, 83-88. 